\title{
Editorial
}

\section{Emphasis on industrial applications}

This year marks my sixth year as editor of Gold Bulletin and I must say year 2001 promises to be a good one from my perspective. Why? Well, maybe it is because World Gold Council, supported by the mining industry, has recognised the importance of promoting the industrial applications of gold if gold is to strengthen its long term future. We have a new strategy to support this goal.

As I said in my previous editorial, promoting industrial usage includes regaining lost share of existing applications such as in electronics and dental as well as developing new applications based on the new science and technology emerging from research laboratories around the world. This will depend not only on the technical merits of gold but also on its economic merits in the application compared to competitive technology. Gold must be good value to succeed.

David Thompson, my Technical Editor, and I are particularly excited about the commercial potential of gold catalysts and are looking forward to the World Gold Councilsponsored International Conference, Catalytic Gold, in Cape Town in early April. Here, researchers and end-users will come together to discuss progress in gold catalyst science and its exploitation. Watch out for a conference report in the next issue of Gold Bulletin.

I must also add that, in September, a further symposium on gold and silver catalysis will be held in September in Limerick, Ireland, as part of the EuropaCat V catalysis conference (see Calendar and page 29 for details). Gold catalysis is moving out from academic research into the limelight of the commercial world in 2001!

\section{Gold Bulletin reverts to free distribution}

As most of you are aware, we introduced a subscription charge last year to help cover our production costs. I must admit that this has not been the success we hoped for. We believe that a wide distribution is important if our goals for industrial applications are to be achieved. Consequently, we are reverting to free distribution this year and that is why you are all getting this copy. We would like a copy to reach all important academic institutions and industry laboratories. Let us know which universities and companies should be on our mailing list. Also, let us know if our mailing list needs updating with your details. Is it addressed to the correct person in your organisation? And does your copy get circulated within your organisation?

Many thanks to those of you who supported us last year.

Enjoy this issue,

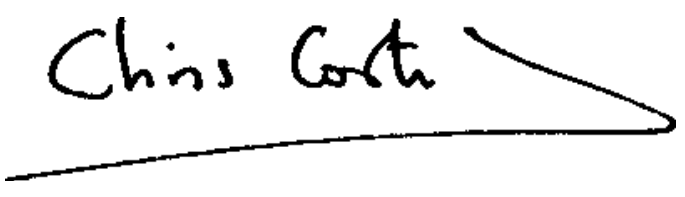

Christopher W Corti

Editor 